\title{
The Endocannabinoid System as Prognostic Biomarker of the Obstructive Sleep Apnea Morbidity in COVID-19-Recovered Individuals
}

\author{
Eric Murillo-Rodríguez ${ }^{1}$ (]
}

Received: 11 May 2021 / Revised: 28 July 2021 / Accepted: 16 September 2021 / Published online: 25 September 2021

(c) The Author(s), under exclusive licence to Springer Nature Singapore Pte Ltd. 2021

\begin{abstract}
The endocannabinoid system is a neurobiological signaling network that is present in the human biological systems, including the brain. This neurobiological system comprises cannabinoid receptors, endogenous ligands, as well as enzymatic synthesis, degradation and transport of endocannabinoids and has been suggested as a modulator of multiple physiological processes, including the sleep-wake cycle. On the other hand, the COVID-19 pandemic, originated by the novel coronavirus SARS$\mathrm{CoV}-2$, has caused global catastrophes in economic, social, and health spheres. COVID-19 is a multi-organ disease with a broad spectrum of health complications, such as respiratory infections leading to respiratory-related symptoms and disorders. The development, approval, and application of vaccines against SARS-CoV-2 is ongoing; however, there are increasing reports of prolonged effects after COVID-19 infection, including respiratory and neurological sequelae. Here, I provide a comprehensive review of the current literature on the endocannabinoid system and their role in sleep modulation. Whilst I discuss relevant considerations for the high risk for developing sleep disorders related to respiratory failures, such as obstructive sleep apnea (OSA) in recovered COVID-19-infected subjects. Finally, I propose a framework that integrates the analysis of the components of the endocannabinoid system as prognostic biomarkers of the likely OSA after COVID-19 infection.
\end{abstract}

Keywords Anandamide · Cannabinoid receptors · COVID-19 - Fatty acid amide hydrolase · SARS-CoV-2

\section{Introduction}

The endocannabinoid system includes a broad range of molecular components such as two G-protein coupled receptors named $\mathrm{CB}_{1}$ and $\mathrm{CB}_{2}$ which recognize their endogenous ligands anandamide (AEA) and 2-arachidonoylglycerol (2-AG) as well as enzymes that participate in the biosynthesis, degradation, and transport of the endocannabinoids $[1,2]$. On the other hand, the World is currently addressing a major pandemic crisis derived from COVID-19. Although eventually vaccines against SARS-CoV-2 will be available, long-term damage to various physiological systems in COVID-19-recovered subjects have been reported, including

Eric Murillo-Rodríguez

eric.murillo@anahuac.mx

1 Laboratorio de Neurociencias Moleculares e Integrativas Escuela de Medicina, División Ciencias de la Salud, Universidad Anáhuac Mayab, Km. 15.5 Carretera Mérida-Progreso, Int. Km. 2 Carretera a Chablekal, C.P. 97308 Mérida, Yucatán, México respiratory and neurological functions. Therefore, greater efforts must be made to develop successful diagnostic approaches for respiratory-related sleep disturbances, such as obstructive sleep apnea (OSA). An emergent insight from the role of the endocannabinoid system on sleep modulation is that this neurobiological network might be part of a new strategy for diagnosis of obstructive OSA in post-infected COVID-19 individuals.

\section{The Endocannabinoid System}

The hemp Cannabis sativa contains over 500 phytocannabinoids including the psychoactive chemical delta-9-tetrahydrocannabinol and the non-psychotropic compound cannabidiol. Whereas the first molecule binds to cannabinoid receptors and exerts a plethora of neurobiological effects, the second compound has been suggested to show no affinity to the cannabinoid receptors but displaying beneficial outcomes in many clinical conditions [3-5]. In the last decades, it has been characterized the components of the 
endocannabinoid system comprising the cannabinoid receptors $\left(\mathrm{CB}_{1} / \mathrm{CB}_{2}\right)$, endogenous ligands (AEA and 2-AG) and their respective metabolizing and synthetic enzymes, as well as membrane transporter $[1,2]$. Furthermore, the localization of the endocannabinoid system in different biological samples has represented a new avenue for research in regards the active role of this neurobiological network in the modulation of health.

\subsection{Synthesis and Degradation of Anandamide and 2-Arachidonoylglycerol}

AEA is formed by the following mechanisms: (a) Free arachidonic acid and ethanolamine (b) the synthesis from $\mathrm{N}$-arachidonoyl phosphatidylethanolamine through the action of a phosphodiesterase $[1,2]$. Once AEA is synthetized, it crosses the membrane with the aid of the anandamide membrane transporter (AMT) for binding to the cannabinoid receptors. Complementary, it has been suggested that AEA is converted into ethanolamine and arachidonic acid by the enzymatic activity of the fatty acid amide hydrolase (FAAH) [6]. On the other hand, the biosynthesis of 2-AG engages membrane phospholipids and the activation of phospholipase $\mathrm{C}$ and diacylglycerol lipase (DAGL) and, once formed, this endocannabinoid binds to the cannabinoid receptors [7]. On the other hand, 2-AG is degraded to arachidonic acid and glycerol by a molecular mechanism that includes the engagement of the monoacylglycerol lipase (MAGL) enzyme [7]. Due to the discovery of the endocannabinoid system elements in the brain [8-11], its role in the modulation of multiple brain functions, including the sleep-wake cycle [12-15], has been suggested.

\section{The Sleep-Wake Cycle}

Based in polysomnogram characteristics, three major states of vigilance have been described in most of the mammals: Wakefulness, slow wave sleep and rapid eye movement sleep. Given the knowledge in the field of the sleep-wake cycle, it would be indeed ambitious to describe the complete evidence in regards the neuroanatomical nucleus and neurochemical systems involved in the control of the sleep; however, this topic has been extensively revised elsewhere [16-23].

\subsection{Circadian and Homeostatic Factors Controlling the Sleep}

The sleep-wake cycle is also under the influence of circadian and homeostatic factors. In regards the circadian rhythms, this natural feature allows temporal patterns for periods of time of $\sim 24 \mathrm{~h}$ to the biological activities of all organisms in the planet. In the case of the sleep-wake cycle, the circadian component is known as Process $C$, which fluctuates within a cycle of $\sim 24 \mathrm{~h}$ and is synchronized by external signals, including the light-dark period [24, 25]. Complementary, the homeostatic process called Process $S$, regulates the deficits of normal biological states and in turn, exerts adjustments. In this regard, the sleep homeostasis is driven by the increase in sleep in response to prolonged waking periods. If sleep deficit reaches a critical point as consequence of sleep deprivation, then the sleep homeostasis mechanism exerts an adjustment by increasing the sleeping time known as "sleep rebound". Thus, sleep pressure dissipates once sleep is onset $[25,26]$.

\subsection{Sleep Disturbances}

The sleep-wake cycle, as many other physiological phenomena, shows aberrant features that have been characterized as sleep disorders [27]. According to the International Classification of Sleep Disorders, several pathological patterns of the sleep have been classified in multiple Axis in which insomnia, central disorders of hypersomnolence, and many others are included.

\section{CovID-19}

The COVID-19 pandemic, originated by the novel coronavirus SARS-CoV-2, has caused worldwide catastrophe in several areas. The clinical manifestation of COVID-19 ranges from asymptomatic/mild symptoms to severe illness and death. The main transmission mechanisms of SARS-CoV-2 are through viral-loaded respiratory droplets generated when an infected patient sneezes or coughs and by direct contact to infected people or contaminated surfaces [28, 29]. Clinical diagnosis of COVID-19 shows it as a multi-organ disease with a broad spectrum of symptoms, such as chest pain, gastrointestinal infections, and respiratory failures, among many others. Precisely because the respiratory system is likely the site where SARS-CoV-2 starts the replication and propagation, severe respiratory-related symptoms and diseases have been identified in patients with COVID-19 [30]. Fortunately, the development, approval, and application of vaccines against SARS-CoV-2 is ongoing [31].

\section{COVID-19, Stress, and Sleep Disturbances}

Once the World Health Organization proclaimed the worldwide sanitary emergency on 2020 of COVID-19, most Countries responded to "flatten the curve" of infections by imposing mandatory measurements including physical distancing, social isolation, and prolonged lockdowns. Over 
time, data emerged on collateral damage due to the lengthened quarantines showed that measurements affected millions of individuals in the World caused by stress derived from unemployment, loneliness, financial and health concerns, isolation, etc. [32-34]. It is worthy to mention that these external stressors have been linked to sleep problems during the prolonged quarantines [35, 36]. For instance, in China, a survey demonstrated that $18 \%$ of respondents claimed poor sleep quality [37]. In line with this Partinen (2021) found an enhancement in the prevalence of sleep disturbances as a collateral effect of COVID-19 crisis due to social isolation [38]. In most of the cases, insomnia was the main sleep disturbance related to stress derived from lockdowns [37-39].

\section{Pulmonary Damage in COVID-19 Patients and Obstructive Sleep Apnea}

Subjects that suffered and recovered from COVID-19 have shown affections in the alveolar epithelial cells as well as lung functioning which have been associated to the persistent dyspnea [40-43]. The impairment in the functioning of the respiratory system impacts on multiple physiological events, including abnormal sleep patterns by the interruption in breathing. This multiple extended pauses in breath are the main clinical manifestation of OSA which fragments the sleep consolidation during the nighttime and seems to be a factor causing insomnia. Thus, on the next waking period, the person complaints of excessive daytime sleepiness. Since subjects recovered from COVID-19 show severe alterations in pulmonary functioning, then it is plausible to assume that these pulmonary sequelae might promote OSA. In despite that the possible mechanism of respiratory system disturbances that leads to sleep disorders remains to be described, it is possible to draw the following hypothesis: Subjects recovered from SARS-CoV-2 infection show effects in the alveolar epithelial cells as well as lung functioning which have been linked to shortness of breath [40-43]. However, we cannot rule out that additional mechanism could be engaged such as alveolar epithelial injury, viral infection of endothelial cells or disorders in the brain respiratory systems $[44,45]$. Unfortunately, there are no data available regarding the clinical association among pulmonary dysfunctions post-COVID-19 infection and OSA morbidity; however, this relationship cannot be discarded.

\section{Beyond Respiratory Damage: COVID-19 Affecting the Brain and Obstructive Sleep Apnea}

At this moment, the major bodies of evidence on COVID19 effecting sleep have been obtained from studies on the stress derived from lockdowns, although I have previously mentioned the possible consequence on the genesis of OSA after lung damage on COVID-19-recovered subjects. However, current data suggest that after infection with SARSCoV-2, some subjects are still battling with several symptoms including neurological sequelae $[40,46]$. This scenario has led to propose that COVID-19 might be able to induce brain damage [47]. Moreover, it is unknown whether OSA might be the result of a disruption in the functioning of the brain respiratory centers, such as medulla oblongata [48], in subjects that suffered COVID-19.

My considerations, as well as their implications, could be the basis of future studies involving large cohorts of recovered subjects from COVID-19 to confirm the hypotheses described here and eventually include the characterization of the neurobiological substrates for such scenarios. However, in line with recent evidence suggesting that COVID19 induces effects in recovered individuals, including brain dysfunctions, I hypothesize that long-term effects of SARS-CoV-2 would alter brain functioning on which the sleep-wake cycle rely.

\section{The Endocannabinoid System and Sleep}

The presence of the endocannabinoid system in the central nervous system represents an interesting framework that seems to modulate multiple brain functions, including the sleep-wake cycle. In this regard, different reports have demonstrated that the $\mathrm{CB}_{1}$ cannabinoid receptors, $\mathrm{AEA}, 2-\mathrm{AG}$, FAAH, and AMT are engaged in sleep control as well in sleep-related phenomena such as circadian and homeostatic regulation. For example, administrations of AEA or 2AG increases sleep whereas the administrations of FAAH enhances wakefulness whereas AMT seems to promote REM sleep. Moreover, the blockade of the $\mathrm{CB}_{1}$ cannabinoid receptor by pharmacological means facilitates alertness. Lastly, current evidence suggests the link between the endocannabinoid system and sleep disturbances, including narcolepsy [12-15, 49-56]. 


\section{The Endocannabinoid System as Prognostic Biomarker of Obstructive Sleep Apnea in COVID-19 Post-Infected Subjects}

The prediction that disturbances in the functioning of the endocannabinoid system is a possible cause of OSA in postCOVID-19 patients is based in the previously mentioned evidence which suggests the active role of this neurobiological network on the modulation of the sleep-wake cycle [15, $57,58]$ as well as the data showing that the endocannabinoids are dysregulated in sleep alterations, including OSA [59-61]. The hypothetical scenario might show that subjects recovered from COVID-19 could show higher serum concentrations of AEA compared to healthy controls, and in turn, display a dysregulation of the anti-inflammatory cytokines, which are activated by the endocannabinoid system [60]. In line with this idea, data have shown that patients with OSA present elevated activity of inflammationrelated molecules [62]. Although the role of the endocannabinoid system in the sleep control has been studied in recent years, there are several gaps that will require further focus, including the characterization of the molecular mechanisms of action by which the endocannabinoids regulate the neurobiological networks linked to the sleep disturbances. Moreover, the lack of evidence suggesting the disruption of the functioning of the endocannabinoid system either during the SARS-CoV-2 infection or after recovery of COVID-19 is limited; however, recent evidence has suggested a likely involvement of the $\mathrm{CB}_{2}$ cannabinoid receptor and COVID-19 [63-66]. Whether additional members of the endocannabinoid system, such as AEA, 2-AG, or FAAH, FAAH, DAGL, MAGL and, AMT, might be affected in post-COVID-19 disease, remains to be determined. Thus, here, I propose some suggestions for moving forward, by including as a new approach for diagnosis of OSA from recovered subjects of SARS-CoV-2 infection: (i) The analysis of the $\mathrm{CB}_{1}$ cannabinoid receptors availability in the cerebral regions involved in the sleep-wake cycle modulation as well as brain nuclei related to breath control by imaging techniques; (ii) the characterization of the endogenous contents of AEA and 2-AG in biological samples, such as plasma or saliva; (iii) the measurement of FAAH, DAGL, MAGL and, AMT in biological tissues. My prediction is that the components of the endocannabinoid system might show abnormal patterns in post-infected COVID-19 individuals. Perhaps these very first reports may provide a descriptive and phenomenological data; however, these findings would suggest that the dysfunctional activity of the endocannabinoid system may represent an alternative tool for diagnostic and eventual development of treatments for the lingering OSA in post-COVID-19-infected subjects.
Indeed, this theoretical construct would merit further study to corroborate and explain my hypothesis. Therefore, future experiments should be aimed at unlocking the precise neurobiological mechanisms through which the endocannabinoid components are related to the likely OSA onset in recovered subjects from COVID-19.

\section{Discussion}

The endocannabinoid system is integrated by the $\mathrm{CB}_{1} / \mathrm{CB}_{2}$ cannabinoid receptors, the endogenous ligands AEA and 2-AG, and their respective metabolizing and synthetizing enzymes, as well as membrane transporter [1,2]. This neurobiological system has been described in multiple human biological samples, including the brain [1, 2, 6-11], suggesting its role on the regulation of a broad neurobiological processes such as the sleep-wake cycle [12-15, 49-58], which is also driven by a variety of neuroanatomical brain areas, neurochemicals, and circadian and homeostatic factors [16-26]. On the other hand, the sleep disorders are the pathological feature of sleep patterns described by the International Classification of Sleep Disorders [27], including insomnia and sleep-related breathing disorders, such as OSA.

The Coronavirus-19 (COVID-19) is a lethal disease that causes flu-like symptoms as well as shortness of breath, gastrointestinal infections, and brain dysfunctions [28-30]. Moreover, mandatory measurements to prevent the spread of COVID-19 including physical distancing, social isolation, and prolonged lockdowns have caused undesirable effects such as stress [32-34]. It is known that stressful conditions are associated to sleep disturbances [35, 36], which have been increased precisely as a result of prolonged lockdowns [37]. Among the sleep disturbances related to COVID-19 crisis, there is evidence showing that OSA is present in COVID-19 patients as consequence of respiratory dysfunction [38-40]. Thus, it is highly possible that patients recovered from COVID-19 might display pulmonary disfunction leading to develop OSA [41, 42]. Moreover, it is worthy to highlight the likely effects on brain activity after even 6 months of COVID-19 infection [44], which may include affections on brain respiratory centers, leading to the establishment of OSA (Fig. 1). Indeed, future studies are needed to discard in COVID-19-recovered patients the disturbances in brain areas related to breathing during sleep, regulation of sleep homeostasis or circadian sleep control as well as the pattern of sleep-related neurochemicals. Perhaps one approach for develop a new diagnostic tool for the likely OSA in COVID-19-recovered subjects may include the analysis of the activity of the components of the endocannabinoid system by testing the endogenous tone of AEA or 


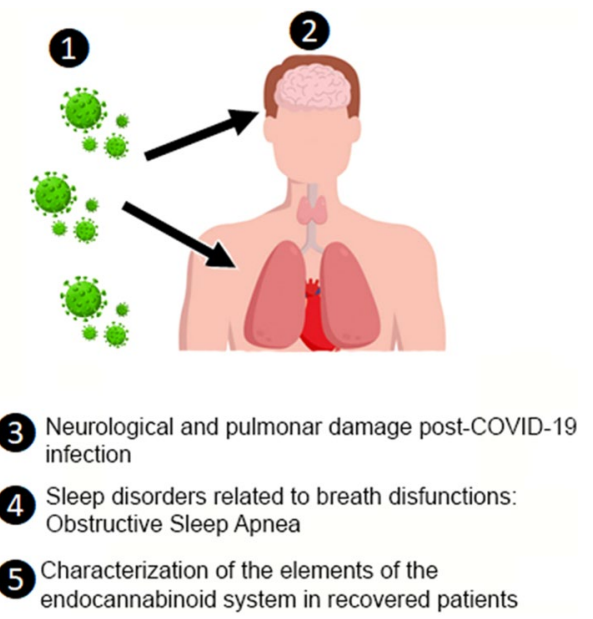

Fig. 1 Hypothetical framework of Obstructive Sleep Apnea (OSA) as consequence of post-infection COVID-19 and the use of the endocannabinoid system as biomarker for diagnosis of OSA. It is likely that long-term pulmonary and neurological effects in COVID-19-recovered subjects may induce sleep disturbances related to breathing, including (OSA). 1: Infection; 2: neuronal and pulmonary damage caused by COVID-19; 3: neuronal and pulmonary disfunctions post-infection of COVID-19; 4: sleep disorders linked to breathing dysfunctions such as OSA; 5: characterization of the elements of the endocannabinoid system in recovered patients from COVID-19

2-AG, as well as the activity of FAAH, AMT, DAGL and, MAGL in sleep-related brain areas. It is therefore expected that the endocannabinoid system might be disrupted in postinfected COVID-19 subjects.

One of the main shortcomings of my hypothesis is the lack of focus on the proximate brain mechanisms triggering OSA in post-COVID-19-recovered subjects. Even though many authors have already proposed that COVID-19 might induce sleep disturbances, limited studies have identified in post-infected individuals. In this regard, recent publications have suggested the likely existence of sleep disorders in post-COVID-19-infected subjects leading to highlight the importance of proper medical counselling [67-69]. In sum, although my considerations might be too speculative, the described body of evidence allows me to propose the study of the components of the endocannabinoid system as diagnostic tool of OSA morbidity in recovered subjects from COVID-19.

\section{Conclusions}

The evidence reviewed here suggests that the involvement of the endocannabinoid system on OSA in recovered people of COVID-19 might represent an inductive and causal reasoning. This idea is backed by the revised evidence. Moreover, the identification of the potential neurobiological mechanisms involved in OSA in recovered subjects of
COVID-19 should support more specific hypotheses and predictions about the attribution of the role of the endocannabinoid components on OSA but also to draw hypothesis in regards the role of COVID-19 post-infected individuals in sleep disorders, including OSA. My considerations also raise a wide range of interesting questions with important diversity for comprehensive understanding in regards the interaction between the components of the endocannabinoid system and the neuroanatomical and neurochemical systems that regulate the sleep-wake cycle. For example, what would be the profile of the sleep-related neurotransmitters in recovered COVID-19 subjects? What is the relationship between the likely circadian disturbed pattern of expression of FAAH and OSA in COVID-19 post-infected individuals? By the examination of the nature and consequences of these questions, we might be provide a new perspective on diagnostical approaches for sleep disturbances in post-COVID19-infected people.

Funding This work was supported by Escuela de Medicina, Universidad Anáhuac Mayab (Grant: PresInvEMR2020) given to EM-R.

\section{Declarations}

Conflict of interest The author declares no conflict of interest.

Ethical Standards All data reported in this paper are from public repositories.

\section{References}

1. Cascio MG, Marini P. Biosynthesis and fate of endocannabinoids. Handb Exp Pharmacol. 2015;231:39-58. https://doi.org/10.1007/ 978-3-319-20825-1_2.

2. Lu HC, Mackie K. Review of the endocannabinoid system. Biol Psychiatry Cogn Neurosci Neuroimaging. 2020;S24519022(20):30206-8. https://doi.org/10.1016/j.bpsc.2020.07.016.

3. Patil AS, Mahajan UB, Agrawal YO, Patil KR, Patil CR, Ojha S, Sharma C, Goyal SN. Plant-derived natural therapeutics targeting cannabinoid receptors in metabolic syndrome and its complications: a review. Biomed Pharmacother. 2020;132: 110889. https:// doi.org/10.1016/j.biopha.2020.110889.

4. Morales P, Reggio PH. Emerging roles of cannabinoids and synthetic cannabinoids in clinical experimental models. Adv Exp Med Biol. 2021;1264:47-65. https://doi.org/10.1007/ 978-3-030-57369-0_4.

5. Dos Santos RG, Hallak JEC, Crippa JAS. Neuropharmacological effects of the main phytocannabinoids: a narrative review. Adv Exp Med Biol. 2021;1264:29-45. https://doi.org/10.1007/ 978-3-030-57369-0_3.

6. Biringer RG. The rise and fall of anandamide: processes that control synthesis, degradation, and storage. Mol Cell Biochem. 2021. https://doi.org/10.1007/s11010-021-04121-5.

7. Murataeva N, Straiker A, Mackie K. Parsing the players: 2-arachidonoylglycerol synthesis and degradation in the CNS. Br J Pharmacol. 2014;171:1379-91. https://doi.org/10.1111/bph.12411. 
8. Rusjan PM, Wilson AA, Mizrahi R, Boileau I, Chavez SE, Lobaugh NJ, Kish SJ, Houle S, Tong J. Mapping human brain fatty acid amide hydrolase activity with PET. J Cereb Blood Flow Metab. 2013;33:407-14. https://doi.org/10.1038/jcbfm.2012.180.

9. Kendall DA, Yudowski GA. Cannabinoid receptors in the central nervous system: their signaling and roles in disease. Front Cell Neurosci. 2017;10:294. https://doi.org/10.3389/fncel.2016.00294.

10. Clapper JR, Henry CL, Niphakis MJ, et al. Monoacylglycerol lipase inhibition in human and rodent systems supports clinical evaluation of endocannabinoid modulators. J Pharmacol Exp Ther. 2018;267:494-508. https://doi.org/10.1124/jpet.118.252296.

11. Redlich C, Dlugos A, Hill MN, et al. The endocannabinoid system in humans: significant associations between anandamide, brain function during reward feedback and a personality measure of reward dependence. Neuropsychopharmacology. 2020;6:1020-7. https://doi.org/10.1038/s41386-020-00870-x.

12. Murillo-Rodríguez E, Machado S, Rocha NB, Budde H, Yuan TF, Arias-Carrión O. Revealing the role of the endocannabinoid system modulators, SR141716A, URB597 and VDM-11, in sleep homeostasis. Neurosci. 2016;339:433-49. https://doi.org/10. 1016/j.neuroscience.2016.10.011.

13. Prospéro-García O, Amancio-Belmont O, Becerril Meléndez AL, Ruiz-Contreras AE, Méndez-Díaz M. Endocannabinoids and sleep. Neurosci Biobehav Rev. 2016;71:671-9. https://doi.org/10. 1016/j.neubiorev.2016.10.005.

14. Murillo-Rodríguez E, Budde H, Veras AB, Rocha NB, Telles-Correia D, Monteiro D, Cid L, Yamamoto T, Machado S, Torterolo $\mathrm{P}$. The endocannabinoid system may modulate sleep disorders in aging. Curr Neuropharmacol. 2020;18:97-108. https://doi.org/10. 2174/1570159X17666190801155922.

15. Kesner AJ, Lovinger DM. Cannabinoids, endocannabinoids and sleep. Front Mol Neurosci. 2020;13:125. https://doi.org/10.3389/ fnmol.2020.00125.

16. Tsunematsu T. Elucidation of neural circuits involved in the regulation of sleep/wakefulness using optogenetics. Adv Exp Med Biol. 2021;1293:391-406. https://doi.org/10.1007/978-981-158763-4_25.

17. Wu Y, Wang L, Yang F, Xi W. Neural circuits for sleep-wake regulation. Adv Exp Med Biol. 2020;1284:v91-112. https://doi. org/10.1007/978-981-15-7086-5_8.

18. Kroeger D, Ferrari LL, Petit G, Mahoney CE, Fuller PM, Arrigoni E, Scammell TE. Cholinergic, glutamatergic, and GABAergic neurons of the pedunculopontine tegmental nucleus have distinct effects on sleep/wake behavior in mice. J Neurosci. 2017;37:v1352-66. https://doi.org/10.1523/JNEUROSCI.1405-16.2016.

19. Monti JM, Jantos $\mathrm{H}$. The effects of local microinjection of selective dopamine D1 and D2 receptor agonists and antagonists into the dorsal raphe nucleus on sleep and wakefulness in the rat. Behav Brain Res. 2018;339:11-8. https://doi.org/10.1016/j.bbr. 2017.11.006.

20. Cissé Y, Toossi H, Ishibashi M, Mainville L, Leonard CS, Adamantidis A, Jones BE. Discharge and role of acetylcholine pontomesencephalic neurons in cortical activity and sleep-wake states examined by optogenetics and juxtacellular recording in mice. eNeuro. 2018. https://doi.org/10.1523/eneuro.0270-18.2018.

21. Yin D, Dong H, Wang TX, Hu ZZ, Cheng NN, Qu WM, Huang ZL. Glutamate activates the histaminergic tuberomammillary nucleus and increases wakefulness in rats. Neuroscience. 2019;413:86-98. https://doi.org/10.1016/j.neuroscience.2019. 05.032 .

22. Menon JML, Nolten C, Achterberg EJM, Joosten RNJMA, Dematteis M, Feenstra MGP, Drinkenburg WHP, Leenaars CHC. Brain microdialysate monoamines in relation to circadian rhythms, sleep, and sleep deprivation-a systematic review, network metaanalysis and new primary data. J Circadian Rhythms. 2019;17:1. https://doi.org/10.5334/jcr.174.
23. Peng W, Wu Z, Song K, Zhang S, Li Y, Xu M. Regulation of sleep homeostasis mediator adenosine by basal forebrain glutamatergic neurons. Science. 2020;369:eabb0556. https://doi.org/10.1126/ science.abb0556.

24. Schibler U, Gotic I, Saini C, Gos P, Curie T, Emmenegger Y, Sinturel F, Gosselin P, Gerber A, Fleury-Olela F, Rando G, Demarque M, Franken P. Clock-talk: interactions between central and peripheral circadian oscillators in mammals. Cold Spring Harb Symp Quant Biol. 2015;80:223-2232. https://doi.org/10.1101/sqb.2015. 80.027490 .

25. Borbély AA, Daan S, Wirz-Justice A, Deboer T. The twoprocess model of sleep regulation: a reappraisal. J Sleep Res. 2016;25:131-43. https://doi.org/10.1111/jsr.12371.

26. Donlea JM, Alam MN, Szymusiak R. Neuronal substrates of sleep homeostasis; lessons from flies, rats and mice. Curr Opin Neurobiol. 2017;44:228-35. https://doi.org/10.1016/j.conb.2017.05.003.

27. Gauld C, Lopez R, Geoffroy PA, Morin CM, Guichard K, Giroux É, Dauvilliers Y, Dumas G, Philip P, Micoulaud-Franchi JA. A systematic analysis of ICSD-3 diagnostic criteria and proposal for further structured iteration. Sleep Med Rev. 2021;58: 101439. https://doi.org/10.1016/j.smrv.2021.101439.

28. Leung NHL. Transmissibility and transmission of respiratory viruses. Nat Rev Microbiol. 2021. https://doi.org/10.1038/ s41579-021-00535-6.

29. Rabaan AA, Al-Ahmed SH, Al-Malkey M, et al. Airborne transmission of SARS-CoV-2 is the dominant route of transmission: droplets and aerosols. Infez Med. 2021;29:10-9.

30. Esakandari H, Nabi-Afjadi M, Fakkari-Afjadi J, Farahmandian N, Miresmaeili SM, Bahreini E. A comprehensive review of COVID-19 characteristics. Biol Proced Online. 2020;22:19. https://doi.org/10.1186/s12575-020-00128-2.

31. Dai L, Gao GF. Viral targets for vaccines against COVID-19. Nat Rev Immunol. 2021;21:73-82. https://doi.org/10.1038/ s41577-020-00480-0.

32. Joffe AR. COVID-19: rethinking the lockdown groupthink. Front Public Health. 2021;9: 625778. https://doi.org/10.3389/ fpubh.2021.625778.

33. Tsamakis K, Tsiptsios D, Ouranidis A, et al. COVID-19 and its consequences on mental health. Exp Ther Med. 2021;21:244. https://doi.org/10.3892/etm.2021.9675 (Review).

34. Gullo S, Misici I, Teti A, Liuzzi M, Chiara E. Going through the lockdown: a longitudinal study on the psychological consequences of the coronavirus pandemic. Res Psychother. 2021;23:494. https://doi.org/10.4081/ripppo.2020.494.

35. Kim EJ, Dimsdale JE. The effect of psychosocial stress on sleep: a review of polysomnographic evidence. Behav Sleep Med. 2007;5:256-78. https://doi.org/10.1080/15402000701557383.

36. Kalmbach DA, Anderson JR, Drake CL. The impact of stress on sleep: pathogenic sleep reactivity as a vulnerability to insomnia and circadian disorders. J Sleep Res. 2018;27: e12710. https:// doi.org/10.1111/jsr.12710.

37. Huang Y, Zhao N. Generalized anxiety disorder, depressive symptoms and sleep quality during COVID-19 outbreak in China: a web-based cross-sectional survey. Psychiatry Res. 2020;288: 112954. https://doi.org/10.1016/j.psychres.2020. 112954.

38. Partinen M. Sleep research in 2020: COVID-19-related sleep disorders. Lancet Neurol. 2021;20:15-7. https://doi.org/10.1016/ S1474-4422(20)30456-7.

39. Kokou-Kpolou CK, Megalakaki O, Laimou D, Kousouri M. Insomnia during COVID-19 pandemic and lockdown: prevalence, severity, and associated risk factors in French population. Psychiatry Res. 2020;290: 113128. https://doi.org/10.1016/j.psych res.2020.113128.

40. Carfî A, Bernabei R, Landi F, Gemelli Against COVID-19 PostAcute Care Study Group. Persistent symptoms in patients after 
acute COVID-19. JAMA. 2020;324:603-5. https://doi.org/10. 1001/jama.2020.12603.

41. Marini JJ, Gattinoni L. Management of COVID-19 respiratory distress. JAMA. 2020;323:2329-30. https://doi.org/10.1001/jama. 2020.6825.

42. Polidoro RB, Hagan RS, de Santis SR, Schmidt NW. Overview: systemic inflammatory response derived from lung injury caused by SARS-CoV-2 infection explains severe outcomes in COVID19. Front Immunol. 2020;11:1626. https://doi.org/10.3389/fimmu. 2020.01626.

43. Parimon T, Yao C, Stripp BR, Noble PW, Chen P. Alveolar epithelial type II cells as drivers of lung fibrosis in idiopathic pulmonary fibrosis. Int J Mol Sci. 2020;21:2269. https://doi.org/10. 3390/ijms21072269.

44. George PM, Wells AU, Jenkins RG. Pulmonary fibrosis and COVID-19: the potential role for antifibrotic therapy. Lancet Respir Med. 2020;8:807-15. https://doi.org/10.1016/S22132600(20)30225-3.

45. Brosnahan SB, Jonkman AH, Kugler MC, Munger JS, Kaufman DA. COVID-19 and respiratory system disorders: current knowledge, future clinical and translational research questions. Arterioscler Thromb Vasc Biol. 2020;40:2586-97. https://doi.org/10. 1161/ATVBAHA.120.314515.

46. Huang C, Huang L, Wang Y, et al. 6-month consequences of COVID-19 in patients discharged from hospital: a cohort study. Lancet. 2021;397:220-32. https://doi.org/10.1016/S01406736(20)32656-8.

47. Boldrini M, Canoll PD, Klein RS. How COVID-19 affects the brain. JAMA Psychiat. 2021. https://doi.org/10.1001/jamapsychi atry.2021.0500.

48. Ikeda K, Kawakami K, Onimaru H, Okada Y, Yokota S, Koshiya $\mathrm{N}$, Oku Y, Iizuka M, Koizumi H. The respiratory control mechanisms in the brainstem and spinal cord: integrative views of the neuroanatomy and neurophysiology. J Physiol Sci. 2017;67:4562. https://doi.org/10.1007/s12576-016-0475-y.

49. Murillo-Rodriguez E, Poot-Ake A, Arias-Carrion O, PachecoPantoja E, Fuente-Ortegon Ade L, Arankowsky-Sandoval G. The emerging role of the endocannabinoid system in the sleepwake cycle modulation. Cent Nerv Syst Agents Med Chem. 2011;11:189-96. https://doi.org/10.2174/187152411798047780.

50. Murillo-Rodríguez E, Palomero-Rivero M, Millán-Aldaco D, Di Marzo V. The administration of endocannabinoid uptake inhibitors OMDM-2 or VDM-11 promotes sleep and decreases extracellular levels of dopamine in rats. Physiol Behav. 2013;109:88-95. https://doi.org/10.1016/j.physbeh.2012.11.007.

51. Hanlon EC, Tasali E, Leproult R, Stuhr KL, Doncheck E, de Wit H, Hillard CJ, Van Cauter E. Circadian rhythm of circulating levels of the endocannabinoid 2-arachidonoylglycerol. J Clin Endocrinol Metab. 2015;100:220-6. https://doi.org/10.1210/jc.2014-3455.

52. Pava MJ, Makriyannis A, Lovinger DM. Endocannabinoid signaling regulates sleep stability. PLoS ONE. 2016;11: e0152473. https://doi.org/10.1371/journal.pone.0152473.

53. Murillo-Rodriguez E, Pastrana-Trejo JC, Salas-Crisóstomo M, de la Cruz M. The endocannabinoid system modulating levels of consciousness, emotions and likely dream contents. CNS Neurol Disord Drug Targets. 2017;16:370-9. https://doi.org/10.2174/ $187152731666617022316190810.2174 / 18715273166661702231$ 61908.

54. Murillo-Rodríguez E, Di Marzo V, Machado S, Rocha NB, Veras AB, Neto GAM, Budde H, Arias-Carrión O, Arankowsky-Sandoval G. Role of $N$-arachidonoyl-serotonin (AA-5-HT) in sleepwake cycle architecture, sleep homeostasis, and neurotransmitters regulation. Front Mol Neurosci. 2017;10:152. https://doi.org/10. 3389/fnmol.2017.00152.

55. Romigi A, Bari M, Liguori C, Izzi F, Rapino C, Nuccetelli M, Battista N, Bernardini S, Centonze D, Mercuri NB, Placidi F,
Maccarrone M. CSF levels of the endocannabinoid anandamide are reduced in patients with untreated narcolepsy type 1: a pilot study. CNS Neurol Disord Drug Targets. 2020;19:142-7. https:// doi.org/10.2174/1871527319666200309115602.

56. Hanlon EC. Impact of circadian rhythmicity and sleep restriction on circulating endocannabinoid (eCB) N-arachidonoylethanolamine (anandamide). Psychoneuroendocrinology. 2020;111: 104471. https://doi.org/10.1016/j.psyneuen.2019.104471.

57. Puskar P, Sengupta T, Sharma B, Nath SS, Mallick H, Akhtar N. Changes in sleep-wake cycle after microinjection of agonist and antagonist of endocannabinoid receptors at the medial septum of rats. Physiol Behav. 2021;237: 113448. https://doi.org/10.1016/j. physbeh.2021.113448.

58. Méndez-Díaz M, Ruiz-Contreras AE, Cortés-Morelos J, Prospéro-García O. Cannabinoids and sleep/wake control. Adv Exp Med Biol. 2021;1297:83-95. https://doi.org/10.1007/ 978-3-030-61663-2_6.

59. Jumpertz R, Wiesner T, Blüher M, Engeli S, Bátkai S, Wirtz $\mathrm{H}$, Bosse-Henck A, Stumvoll M. Circulating endocannabinoids and $\mathrm{N}$-acyl-ethanolamides in patients with sleep apnea-specific role of oleoylethanolamide. Exp Clin Endocrinol Diabetes. 2010;118:591-5. https://doi.org/10.1055/s-0030-1253344.

60. Wang X, Yu Q, Yue H, Zhang J, Zeng S, Cui F. Circulating endocannabinoids and insulin resistance in patients with obstructive sleep apnea. Biomed Res Int. 2016;2016:9782031. https://doi.org/ 10.1155/2016/9782031.

61. Babson KA, Sottile J, Morabito D. Cannabis, cannabinoids, and sleep: a review of the literature. Curr Psychiatry Rep. 2017;19(4):23. https://doi.org/10.1007/s11920-017-0775-9.

62. Unnikrishnan D, Jun J, Polotsky V. Inflammation in sleep apnea: an update. Rev Endocr Metab Disord. 2015;16(1):25-34. https:// doi.org/10.1007/s11154-014-9304-x.

63. Lucaciu O, Aghiorghiesei O, Petrescu NB, Mirica IC, Benea HRC, Apostu D. In quest of a new therapeutic approach in COVID19: the endocannabinoid system. Drug Metab Rev. 2021;8:1-13. https://doi.org/10.1080/03602532.2021.1895204.

64. Rossi F, Tortora C, Argenziano M, Di Paola A, Punzo F. Cannabinoid receptor type 2: a possible target in SARS-CoV-2 (CoV-19) infection? Int J Mol Sci. 2020;21:3809. https://doi.org/10.3390/ ijms21113809.

65. Cinar R, Iyer MR, Kunos G. Dual inhibition of $\mathrm{CB}_{1}$ receptors and iNOS, as a potential novel approach to the pharmacological management of acute and long COVID-19. Br J Pharmacol. 2021. https://doi.org/10.1111/bph.15461.

66. Nagoor Meeran MF, Sharma C, Goyal SN, Kumar S, Ojha S. CB2 receptor-selective agonists as candidates for targeting infection, inflammation, and immunity in SARS-CoV-2 infections. Drug Dev Res. 2021;82:7-11. https://doi.org/10.1002/ddr.21752.

67. Gupta R, Pandi-Perumal SR. SARS-CoV-2 infection: paving way for sleep disorders in long term! Sleep Vigil. 2021. https://doi.org/ 10.1007/s41782-021-00145-5.

68. Kar A, Saxena K, Goyal A, Pakhare A, Khurana A, Saigal S, Bhagtana PK, Chinta SSKR, Niwariya Y. Assessment of obstructive sleep apnea in association with severity of COVID-19: a prospective observational study. Sleep Vigil. 2021. https://doi.org/ 10.1007/s41782-021-00142-8.

69. Goyal A, Kar A, Saxena K. COVID eyes: REM in COVID19 survivors. Sleep Vigil. 2021. https://doi.org/10.1007/ s41782-020-00124-2.

Publisher's Note Springer Nature remains neutral with regard to jurisdictional claims in published maps and institutional affiliations. 